\title{
Chapter 13 \\ Investing in Others: Prosocial Spending for (Pro)Social Change
}

\author{
Lara B. Aknin, Gillian M. Sandstrom, Elizabeth W. Dunn, \\ and Michael I. Norton
}

Imagine the following: It is a Saturday morning in December and you have decided to have breakfast at your local diner. You take a seat in a booth by the window and order the usual - a mushroom and cheese omelet with a side of hash browns and a coffee. As you enjoy your omelet, you consider your plans for the day. You have a long list of errands to attend to before heading to a friend's place tonight, so as soon as you finish your meal, you summon your waitress for the check. She makes her way to your table and tells you that your check has been paid by another customer who just left the diner and then adds, "Happy Holidays." Your bill was not large, but you are emotionally moved by the kindness of this generous act. You reach for your wallet anyway and tell the waitress you would like to pay the check for the next table. You leave $\$ 20$ and head out the door with a smile. And just like that, a favor has been paid forward.

This may sound more like a scene from a movie than real life, but this is just what happened in a Philadelphia diner in the winter of 2009 (Johnson, 2009). The positive chain reaction was initiated by an unknown couple who paid for their bill and the bill of another customer. The couple did not leave their names or phone number, but simply asked that the waitress wait until they had left the restaurant before informing the other customer that their tab had been paid. This act inspired others to do the same. For the next $5 \mathrm{~h}$, dozens of customers continued to pay the favor forward. The staff at the diner were amazed by the string of generous spending, so much so that one waitress reported that the "magical" event brought tears to her eyes.

This occurrence provides a poignant example of how prosocial spending, that is, spending money on others, can lead to positive outcomes for the people spending the money, those receiving it, and even other individuals nearby. In this chapter, we unpack and explore the possibility of prosocial spending as a mechanism for positive social change. After providing some background, we review our research on the happiness benefits of prosocial spending. We discuss the impact of prosocial spending at four levels, starting first with the happiness benefits of prosocial spending for individuals, and then extending this discussion outward to dyads, to

\author{
E.W. Dunn $(\bowtie)$ \\ University of British Columbia, Vancouver, BC, Canada \\ e-mail: edunn@psych.ubc.ca
}


teams, and to organizations. Finally, we offer several practical strategies for utilizing this prosocial spending research, applying the findings of some of our newest research to propose ways in which prosocial spending can produce the largest benefits.

\section{The Relationship Between Money and Happiness}

Scholars ranging from economists and psychologists to sociologists and philosophers have explored the relationship between money and happiness (e.g., Diener \& Seligman, 2004; Kahneman, Krueger, Schkade, Schwarz, \& Stone, 2006; Layard, 2005; Oswald, 1997; Veenhoven, 1991). Understanding this relationship is important because many people spend a large part of their lives working to accumulate wealth, driven in part by the belief that income is closely related to happiness (Ahuvia, 2008; Kahneman et al., 2006). The majority of studies conducted over the past several decades examining the link between money and happiness have used correlational designs, and suggest that money has a small but significant effect on happiness within developed nations (e.g., Diener \& Biswas-Diener, 2002; Frey \& Stutzer, 2000). Interestingly, however, it seems that people overestimate how much happiness money can bring: When we asked a nationally representative sample of Americans to predict how happy they would be at various levels of income, participants envisioned a much steeper relationship between money and happiness than the actual data revealed (Aknin, Norton, \& Dunn, 2009). Yet, while absolute levels of income may not matter as much for happiness as most people may believe, we suggest that how people spend their money may be as important for their happiness as how much they earn. Indeed, while there are several reasons why income may have a weak effect on well-being, one possibility is that people choose to invest their increased wealth into spending choices that provide little in the way of lasting happiness gains. As economist Robert Frank (2004) has suggested, money might be able to increase well-being if people were to spend it wisely. Thus, instead of using increased wealth to buy material purchases, like bigger homes and faster cars, we suggest - and our research demonstrates - that people should spend their money in service of goals that have been shown to increase happiness, such as investing in other people through kind or generous acts.

Whereas wealth has been shown to have a relatively small impact on happiness, an emerging body of research suggests that engaging in prosocial behavior can increase well-being. This relationship has been well-documented through correlational methods (Aderman, 1972; Cunningham, Steinberg, \& Grev, 1980; Lucas, 2001; Rosenhan, Underwood, \& Moore, 1974; Williams \& Shiaw, 1999) and, more recently, with experimental design (Lyubomirsky, Sheldon, \& Schkade, 2005). For example, Lyubomirsky and colleagues showed that students assigned to perform five random acts of kindness a week for 6 weeks were happier than those in a no-action control group. Given that prosocial behavior has been shown to increase happiness, our work has sought to test whether using money to this end could increase happiness as well. Specifically, we hypothesized that prosocial spending, through gift 
giving and charitable donations, would lead to higher happiness levels than spending money on oneself.

\section{Prosocial Spending at the Individual Level}

Initial Evidence. In an initial study, we asked a nationally representative sample of Americans to rate their general happiness and to estimate their monthly personal and prosocial spending (Dunn, Aknin, \& Norton, 2008). Specifically, participants reported the funds they devoted in a typical month to personal spending (bills, expenses, and gifts for themselves) and to prosocial spending (gifts for others and donations to charity). Individuals who spent more money in a typical month on prosocial spending reported greater happiness, whereas personal spending was unrelated to happiness. Importantly, this relationship remained even when controlling for annual household income. While these results provide a promising first step in linking prosocial spending and happiness in the population, the correlational nature of this study does not allow us to ascertain the direction of the relationship; it is possible that, instead of indicating that prosocial spending leads to happiness, the relationship simply shows that happier people are more likely to engage in prosocial spending.

Therefore, we next used an experimental design to examine whether spending money on others leads to higher happiness levels than spending money on oneself (Dunn et al., 2008). Participants were approached in person during the morning hours in public places and reported their baseline happiness level. After doing so, participants were randomly assigned to one of four spending conditions, receiving either $\$ 5$ or $\$ 20$ to spend on either themselves or others. Participants in the personal spending condition were asked to spend their windfall on a bill, expense, or gift for themselves, while participants in the prosocial spending condition were asked to spend their windfall on a gift for someone else or a donation to charity. Participants were asked to spend the money before the end of the day, when a research assistant would call them with a series of follow-up questions. As predicted, participants who spent their windfall prosocially were happier at the end of the day than participants who spent the windfall on themselves. Interestingly, the amount of money that participants received (\$5 or \$20) did not influence happiness levels, suggesting that how people spent their money was more important than how much money they spent. Therefore, this experimental study provides support for the causal claim that spending money on others leads to higher happiness than spending money on oneself.

While it is not surprising that people devote a large portion of their income to personal spending - after all, people need to pay the bills - we explored whether the relative infrequency with which people engaged in prosocial spending might be linked to a misunderstanding of its emotional benefits. We examined whether people recognize that spending money on others will make them happier than spending money on themselves by asking another group of participants to read brief descriptions of the four conditions in the experimental study and predict which spending 
condition would make them happiest (Dunn et al., 2008). A significant majority of participants reported believing that spending money on themselves would make them happier than spending the money on someone else, suggesting that people overlook the happiness returns associated with prosocial spending.

International Replication. While the studies discussed above demonstrate that spending money on others leads to higher happiness than spending money on oneself, it is important to note that these studies were conducted in North America. Because previous research has shown that the relationship between money and happiness can vary depending on a country's wealth (Deaton, 2008; Diener \& Biswas-Diener, 2002), a critical question is whether prosocial spending will lead to similar happiness increases when disposable income is limited. To examine this question, we examined the responses of over 230,000 participants drawn from 136 countries in the Gallup World Poll (Aknin et al., 2010). Respondents reported their overall well-being and whether or not they had donated money to charity in the past month. The relationship between prosocial spending and well-being was positive in 122 out of 136 countries around the world, even after controlling for individuals' household income. Importantly, the relationship was unrelated to the average income of each country, suggesting that donating money to charity has emotional benefits in rich and poor countries alike. Given the large number of countries showing a positive relationship between prosocial spending and well-being, this research highlights the possibility that the emotional benefits associated with spending money on others are universal.

Beyond Immediate Mood Benefits. The data described above suggest that the emotional benefits of prosocial spending can be detected around the globe, but another important question concerns the endurance of the mood boosts associated with prosocial spending. Our initial experimental investigations focused on the short-term benefits of spending money on others by comparing participants' selfreports from the morning and evening of a single day. Given the possibility that the mood benefits resulting from prosocial spending could quickly fade, some of our more recent work has examined whether the mood benefits can accrue over time; when people think back to a time when they engaged in prosocial spending, do they experience increased happiness from that remembered utility? We asked a sample of more 600 participants from Canada and Uganda to recall and describe in detail the last time they spent a small sum of money on themselves or someone else (Aknin et al., 2010). After describing this spending experience, participants reported their current level of happiness. Participants who recalled a time they spent money on others reported higher levels of happiness than participants who recalled a time they spent money on themselves. Thus, the emotional benefits of prosocial spending persist beyond the hours immediately following spending, and are accessible when thinking back at a later time. Importantly, the lasting emotional benefits of prosocial spending have been shown in both Canada and Uganda, again suggesting that these findings are not limited to participants in North America.

Sustainable Happiness: A Positive Feedback Loop between Happiness and Prosocial Spending. The research described above demonstrates that engaging in 
and recalling an act of prosocial spending both lead to higher levels of happiness, but do higher levels of happiness, in turn, promote acts of prosocial spending? Classic work by Isen and colleagues (e.g., Isen, 1970; Isen \& Levin, 1972) showed that experimentally induced positive moods - produced by receiving cookies or finding a dime - led to higher levels of helping in a subsequent task. More recent work has shown this is also the case with naturally occurring moods: Happier people are more likely to give a donation in an anonymous economic exchange (Konow \& Early, 2008). Indeed, research on volunteering and prosocial behavior suggests that the relationship between prosocial behavior and happiness may be bidirectional. That is, happier people are more likely to engage in helping behavior and to experience higher levels of happiness from doing so (e.g., Piliavin, 2003; Thoits $\&$ Hewitt, 2001). Given that prosocial spending represents one form of prosocial behavior, we wondered whether happiness and prosocial spending may also reinforce one another in a positive feedback loop. Specifically, we examined whether recalling a previous act of prosocial spending made people happier and whether higher levels of happiness lead people to select a prosocial spending act in the future.

To investigate this question, we asked participants to think back and describe, in as much detail as possible (Strack, Schwarz, \& Gschneidinger, 1985), the last time they spent either $\$ 20$ or $\$ 100$, either on themselves or on someone else (Aknin, Dunn, \& Norton, 2010, unpublished data). After describing this experience, each participant reported their current level of happiness. Next, each participant was asked to select the future spending behavior they thought would make them happiest: spending either $\$ 5$ or $\$ 20$, either on themselves or on someone else. As observed before, participants who were asked to recall a time they spent money on someone else were happier than parrticipants who were asked to recall a time they spent money on themeselves, regardless of the amount of money spent. To test for the existence of a postive feedback loop between happiness and prosocial spending, we also examined whether these elevated levels of happiness were associated with future spending choice. Analyses confirmed that higher levels of happiness significantly predicted a preference for future prosocial spending. Thus, these data suggest that prosocial spending and happiness mutually reinforce each other in a postive feedback loop.

Health Outcomes. Given that prosocial spending is consistently linked with emotional well-being, we sought to investigate whether prosocial spending might also hold downstream consequences for physical well-being. Previous research has demonstrated that emotional responses to stress represent a pathway through which psychosocial variables can influence physical health (e.g., Cohen \& Pressman, 2006; Polk, Cohen, Doyle, Skoner, \& Kirschbaum, 2005). In addition, emotional responses to psychosocial events have been shown to activate the hypothalamicpituitary-adrenal (HPA) axis (Polk et al., 2005), which regulates the release of the stress hormone cortisol. While elevated levels of cortisol secretion in response to stress may be adaptive in the short-term, frequent or prolonged elevation of cortisol in response to stress can inhibit immune functioning and increase the likelihood of 
disease (McEwen, 1998). Because the emotional responses provoked by stress shape the secretion of cortisol (Dickerson \& Kemeny, 2004; Polk et al., 2005), we wondered whether generous and stingy economic decisions could influence emotional responses and thereby shape cortisol levels.

To examine whether physiological responses are sensitive to the economic decisions people make, we measured participants' feelings and cortisol levels before and after participation in a well-studied economic game called the "dictator game" (Dunn, Ashton-James, Hanson, \& Aknin, 2010). Students in a large undergraduate class reported their general happiness and provided a baseline sample of cortisol by chewing on a cotton roll. Afterward, half the participants were informed that they had been randomly assigned to the decision-maker role in the upcoming economic game and were given ten $\$ 1$ coins that they could keep for themselves or share with a yoked recipient in the classroom. Decision makers delivered the funds to the recipient and informed the recipient of the donation amount. After delivering their donations, decision makers immediately reported their current affect levels and then provided cortisol samples 15 and 45 minutes after the exchange. As expected, larger donations were associated with higher positive affect and lower negative affect and shame. Importantly, these findings held even when accounting for preexchange happiness ratings, which means that the size of the donation predicted post-exchange affect over and above initial happiness levels. Analyses confirmed our prediction that stingy economic decisions resulted in higher post-exchange cortisol levels by increasing shame. That is, to the extent that low donation amounts led decision makers to feel shame, they were likely to show elevated levels of cortisol. Thus, taken together, these results suggest that personal and prosocial spending, as measured by selfish and generous dictator game decisions, may have downstream consequences for health.

Putting the "Social" in Prosocial Spending: The Importance of Social Connection in Prosocial Spending. In several studies, spending money on others has been shown to lead to higher levels of happiness than spending money on oneself; but what is it about prosocial spending that leads to these happiness gains? Only a handful of studies have investigated this question, but the results suggest that the increased social connection encouraged by prosocial spending may be critical. That is, when spending money on others fosters positive interpersonal contact, prosocial spending is particularly likely to enhance well-being.

A recent study we conducted examined happiness levels after giving to charity (Aknin, Dunn, Sandstrom, \& Norton, 2010, in preparation). Participants reported their happiness and then viewed a printed ad for a charity that helps bring fresh water to the people of Africa and were asked if they would like to donate to the cause. Some participants were told that the charity was of special importance to the research assistant. In another condition, no link was provided between the research assistant and the charity, and donations were made anonymously by putting the desired donation amount in a sealed envelope. Finally, participants again reported their well-being, on a different measure. When the research assistant was personally connected to the cause, participants who gave larger donations reported higher levels of happiness after giving, over and above their initial happiness levels. However, 
larger donations given to the research assistant with no connection to the charity did not lead to an increase in happiness.

The importance of social contact for the mood benefits of prosocial spending has also been replicated with person-to-person spending (Aknin et al., 2010, in preparation). We contacted participants in the morning hours and gave them a Starbucks gift card to spend by the end of the day. We asked participants to spend the gift card on someone else in a way that either maximized or minimized social contact. When participants were contacted on the same evening, they reported the highest happiness when the gift card was used to maximize social contact. That is, participants who spent the gift card on both themselves and someone else by visiting Starbucks together were happiest at the end of the day. Taken together these results suggest that the happiness benefits of prosocial spending are greatest when giving occurs in a social fashion.

In summary, spending money on others has been linked to a variety of positive outcomes for the spender. At the emotional level, prosocial spending has been shown to cultivate happiness gains immediately after giving, at the end of the day, and when an act of prosocial spending is reflected upon later. Moreover, these findings are not limited to North America; the well-being benefits of prosocial spending appear consistently in most countries around the world. Further, it seems that happiness and prosocial spending may mutually reinforce one another in a positive feedback loop, such that prosocial spending increases happiness and happiness increases prosocial spending. At the physiological level, generous and stingy monetary decisions have been shown to impact the body's stress response. Finally, it seems that the emotional benefits of prosocial spending are greatest when the giving is linked to an interpersonal context.

\section{Prosocial Spending at the Dyadic Level}

Having discussed the benefits of prosocial spending for the spender, we now consider the effects of prosocial spending for the recipient. Indeed, considering that the mood benefits of prosocial spending for the giver seem to hinge upon interpersonal interaction with the receiver, examining the impact on that receiver is a logical next step.

There are theoretical reasons to suspect that acts of prosocial spending may have positive benefits for the recipient. At the most basic level, receiving gifts may increase the recipient's well-being through the experience of gratitude. Gratitude is a positive emotion produced when someone feels they have benefited from the intentional, costly, and voluntary actions of someone else (Emmons \& McCullough, 2003; McCullough, Kimeldorf, \& Cohen, 2008). Expressions of gratitude have been shown to produce emotional benefits (Emmons \& McCullough, 2003) and to encourage future acts of prosocial behavior in both the giver and the recipient (McCullough, Emmons, \& Tsang, 2002; McCullough, Kilpatrick, Emmons, \& Larson, 2001). Importantly, gratitude may increase positive affect by creating and strengthening social bonds (Algoe, Haidt, \& Gable, 2008; Emmons \& McCullough, 
2003). In addition, a recipient's happiness may fluctuate with the happiness of others around them (Fowler \& Christakis, 2008). Indeed, people have been shown to catch and match the emotional states of others in even brief interactions through processes such as emotional contagion and mimicry (Hatfield, Cacioppo, \& Rapson, 1993). Therefore, if spenders perform acts of prosocial spending that allow for contact with the recipient, happiness may spread from the spender to the recipient.

To investigate whether prosocial spending has positive outcomes for the recipient, we measured the happiness of both givers and receivers in an experiment using the dictator game (Aknin et al., 2010, in preparation). Participants were given a short questionnaire to report their baseline happiness and were randomly assigned to either the dictator or receiver role in the upcoming monetary exchange. Dictators were given ten $\$ 1$ coins and were asked to decide how much of this $\$ 10$ sum, if any, they would like to keep for themselves and how much they would like to share with their yoked receiver. Importantly, half of the dictators makers were told that they would have to deliver the donation in person and notify the receiver of the amount. Dictators in the other condition were told that a research assistant would deliver their donation. Once recipients received their donations, all participants reported their current affect levels.

To examine whether prosocial spending led to happiness gains for receivers, we tested whether receiving larger donations predicted greater happiness. However, we suspected that the happiness benefits of prosocial spending might hinge upon whether the donation was received directly from the dictator (direct social contact) or by way of a research assistant acting as an intermediary. That is, just as prosocial spenders reported increased happiness after giving in a truly social context, so too might receivers reap the largest emotional benefits of receiving money when the funds are given through direct social contact. Supporting the importance of social connection for happiness, analyses revealed that larger donations were only associated with higher happiness for the recipient when the giving took place in an interpersonal fashion. These findings suggest that it is not simply the experience of receiving a gift or money that increases happiness: Prosocial spending appears to have emotional benefits for the receiver if monetary gifts are transferred in a way that allows direct social contact.

\section{Prosocial Spending at the Team Level}

We now move beyond the dyad level of analysis and examine whether prosocial spending has benefits for teams and small groups. Having established that emotional gains of prosocial spending are experienced by both spenders and recipients when spending occurs in a dyadic context, we go one step further and examine whether spending money on others can produce measurable benefits for entire teams of individuals. Previous research has demonstrated that happiness can spread through large social networks (Fowler \& Christakis, 2008); indeed, the happiness of one individual can spread up to three degrees of separation, influencing the happiness of one's friends' friends' friends. Within a single team, the moods and happiness 
of members are often linked, and are associated with subjective ratings of member performance (Totterdell, 2000). Therefore, we explored whether assigning team members to spend money on a teammate could lead to greater team success.

To investigate this question we recruited intramural dodge ball teams and pharmaceutical sales teams to complete a study on teams and emotions (Norton, Aknin, Anik, Dunn, \& Quoidbach, in preparation). Each team was randomly assigned to either the personal or prosocial spending condition. On teams assigned to the personal spending condition, one to four team members (approximately 20-35\% of the team) were randomly selected to receive $\$ 20$ (or $€ 15$ ) to spend on themselves in the next week. On teams assigned to the prosocial spending condition, one to four team members (approximately $20-35 \%$ of the team) were randomly selected to receive $\$ 20$ (or $€ 15$ ) to spend on a randomly assigned teammate.

We measured performance for both dodge ball and sales teams before and after the spending intervention. In both contexts, prosocial spending teams were more successful than personal spending teams after the spending intervention; dodge ball teams won a higher percentage of their games and sales teams sold more product. Importantly, personal spending teams did not perform more poorly over time; rather it was the prosocial spending teams whose performance improved. Thus, these findings suggest that while personal spending may not influence team outcomes, prosocial spending may improve team success. Indeed, a closer look at the prosocial spending pharmaceutical sales teams shows that the money invested for teammates to spend on each other was returned twofold in team sales.

\section{Prosocial Spending at the Organizational Level}

The previous section discusses the benefits prosocial spending can have for sports and sales teams, but do the positive outcomes extend even further? Small work teams are situated within larger organizations, raising the possibility that if large establishments were to facilitate prosocial spending, similar rewards may materialize for the employee and organization.

To investigate the benefits of engaging in prosocial spending at the organizational level, we conducted a study with employees at an Australian bank (Norton et al., in preparation). Participants completed an online survey, reporting their baseline happiness and job satisfaction. Two weeks later, participants randomly assigned to the prosocial spending conditions were informed that their company had given them either a $\$ 50$ or a $\$ 100$ voucher that they could donate to the charity of their choice, via a website where they could select from over 100 charitable causes. Participants in both conditions then completed a final survey in which they reported their current job satisfaction and happiness.

Participants who allocated $\$ 100$ to charity reported a significant gain in happiness over the 2-week period. However, participants in the control condition and those that allocated \$50 did not show the same increase in happiness. Similarly, participants who allocated $\$ 100$ to charity reported a significant increase in job satisfaction, whereas participants in the control condition and those that allocated $\$ 50$ did not 
show the same job satisfaction increase. While it is unclear why the happiness and job satisfaction gains would only materialize for participants who allocated $\$ 100$ to charity, it is interesting to note that neither of these effects were influenced by tenure with the company. Thus, it appears that the benefits associated with engaging in larger acts of prosocial spending are equally accessible to all employees, regardless of length of employment.

These data show that prosocial spending can have benefits in the workplace. Employees assigned to donate a relatively large monetary sum to charity on behalf of their employer reported increased happiness and job satisfaction. These findings may be particularly pertinent given the current economic climate, with the percentage of Americans reporting dissatisfaction with their job at an all time high; in a 2009 survey, only $45 \%$ of American workers said they are satisfied in their current position (Aversa, 2010). Given that prosocial spending provides such a simple way to increase employee happiness and satisfaction, this strategy may be a worthwhile and cost effective intervention for companies. Further, this study demonstrates that prosocial spending interventions need not be an economic burden for companies. Simply allowing employees to distribute a firm's allotted charitable funds through personalized donations can lead to positive results.

\section{Onward and Outward}

Could acts of prosocial spending spiral outward? After benefiting from an act of prosocial spending in an everyday transaction, are people more likely to engage in prosocial behavior themselves? To find out, we went to the drive-thru at a local coffee shop and paid for the order of randomly selected customers behind us in the drive-thru line up (Aknin et al., 2010, in preparation). Because the coffee shop was collecting donations for a children's charity that day, all customers were asked if they would like to donate to this particular cause. Customers who found out that their bill had been paid were significantly more likely to donate to charity. Of course, customers who received an act of prosocial spending may have been more likely to donate money because they had just received their order for free; these customers may have simply donated the money they had already mentally allocated for their order. While this is a possibility, almost half of the participants who received an act of prosocial spending donated more than the price of their bill. These findings offer some preliminary evidence to suggest that being the beneficiary of prosocial spending may inspire individuals to pay the favor forward, leading to positive outward spirals of prosocial behavior.

Given the positive outcomes associated with giving and receiving prosocial spending described above, it should come as no surprise that companies have tried incorporating these principles in creative ways (Anik, Aknin, Norton, \& Dunn, 2010). For example, in fall 2009, Banana Republic stores in New York City invited representatives from various charities to mingle with their customers and offer information on ways to get involved (Wilson, 2009). This campaign, coordinated by ServiceNation, was designed to pair potential donors and volunteers with a cause 
suited to their interest. Banana Republic sees value in this campaign, according to their president, Jack Calhoun, because they believe their customers care about things other than fashion (Wilson, 2009). Indeed, helping individuals find a cause to which they can contribute is only one way companies have aligned themselves with prosocial behavior. Other companies have taken to offering consumers the chance to donate to causes through the purchase of specific products. For example, MAC Cosmetics, Apple, and Motorola have all sold specialty products with partial proceeds dedicated to philanthropic causes, such as AIDS research (Barbaro, 2009). Thus, these examples present a glimpse at some of the many ways companies have assimilated prosocial programs into their business practices.

\section{Why Does Prosocial Spending Increase Happiness? New Theoretical Questions and Applications}

Having reviewed our program of research on prosocial spending, we now consider why prosocial spending may increase happiness. While no study has isolated a single feature of prosocial spending responsible for the observed effects, clues may be gleaned by returning to earlier findings reported in this chapter. Specifically, several studies demonstrated that acts of prosocial spending such as giving a donation or gift card lead to the greatest happiness gains when the giving allowed for positive interpersonal contact. Thus, these findings suggest that one reason prosocial spending produces hedonic gains is because spending money on others, when done in a social manner, can contribute to and facilitate the development of social relationships. This interpretation dovetails with previous research demonstrating that strong social relationships are a key predictor of happiness (Myers, 2000). Indeed, very happy people report having more satisfying relationships than their peers (Diener \& Seligman, 2002), and having a number of positive and supportive social relationships may also serve to satisfy our fundamental need to belong (Baumeister \& Leary, 1995; Deci \& Ryan, 1985; Ryan \& Deci, 2000). Of course, engaging in acts of prosocial spending cannot guarantee that an individual will have strong social relationships. However, to the extent that spending money on others encourages positive social interactions, prosocial spending may foster social networks.

The relationship between prosocial spending and happiness may be further elucidated by the Broaden and Build theory of positive emotions (Fredrickson, 1998, 2001, 2004). According to this theory, positive emotions produce favorable outcomes in the present and future. Parallel to theories examining the action tendencies triggered by negative emotions, the Broaden and Build theory suggests that positive emotions serve to broaden an individual's thoughts and build enduring resources. Happiness, a positive emotion, may broaden one's mindset and promote the building of future resources through the formation and augmentation of social relationships. Support for this argument can be seen in the mutually reinforcing nature of happiness and prosocial spending. For instance, the finding that higher levels of happiness encourage a future willingness to spend on others suggests that happiness may 
expand an individual's mindset beyond the typical preference for personal spending (Dunn et al., 2008) to incorporate thoughts of others. Further, happiness, in turn, leads people to build their present and future resources by strengthening their social bonds through acts of prosocial spending. Thus, prosocial spending leads to higher levels of happiness when conducted in social ways that facilitate social bonding, which fuels a mutually reinforcing positive feedback cycle.

This theoretical explanation fits with real-world examples of how people choose to engage in prosocial spending and suggests applications for how best to invest in others (Aknin et al., 2010, in preparation). A desire for positive interpersonal contact helps explain why the majority of prosocial spending occurs between two acquainted individuals. For example, less than $1 \%$ of the money raised by charitable organizations in 2008 was collected from online donations, suggesting that donors may prefer to make donations in more socially significant ways, such as donating to friends, family, or co-workers raising money for the cause (Barton \& Wasley, 2009). Further, fewer than $2 \%$ of donations by college alumni to their alma mater are made in an anonymous fashion (Glazer \& Konrad, 1996). Finally, these findings coincide with reports suggesting that one of the most common reasons donors offer for their charitable behavior is personal experience with the recipient (Schervish \& Szanto, 2006) or because they were asked by someone (Independent Sector, 1999).

Thus, these studies suggest that applications of prosocial spending should encourage increased social connection. One easy way for this to occur is to promote face-to-face prosocial spending whenever possible. If someone decides to make a donation or give a gift, they should try to give directly to the recipient or someone with a vested interest. For example, taking a friend out for a birthday dinner would lead to higher levels of happiness than mailing your friend a restaurant gift card for an equivalent amount. This direct act of prosocial spending will not only produce happiness gains for the spender, but will lead to higher happiness for the receiver as well. When this type of direct giving is not possible, it may be beneficial to increase connection in other ways. For example, the online charity organization DonorsChoose.org connects contributors to their selected classroom charity project with student and teacher thank you notes as well as pictures of the classroom. Through these forms of interaction, donors feel connected to the cause, can see the results of their donation, are more likely to feel the hedonic boosts of giving, and may be more likely to give again in the future.

Of course, the extent to which prosocial spending increases happiness hinges upon other factors as well. For instance, the mood benefits associated with prosocial spending may depend upon the degree to which the act affirms one's values. This notion, from (Lyubomirsky et al., 2005) theory of person-activity fit, suggests that an individual's preferences, strengths, and interests predispose some people to benefit most from certain happiness-increasing interventions. Therefore, the degree of consistency between an individual's values and those of the prosocial spending beneficiary may influence whether and how much happiness is gained from prosocial spending. Thus, giving to an individual or cause that one believes important or deserving may lead to larger emotional boosts. Similarly, the method in which prosocial spending is enacted may also enhance or inhibit happiness gains. That is, 
while acts of prosocial spending made in a social context may increase happiness for most people (as observed in several of the studies presented here), other individuals may prefer to give in a more private setting. Finally, alternating the ways in which prosocial spending is conducted may also be important. Research conducted by Sheldon, Boehm, and Lyubomirsky (in press) has shown that participants who committed kind acts for others over the course 10 week intervention showed the greatest well-being gains when these behaviors were enacted in a variety of ways. Thus, when implementing extended prosocial spending interventions, it may be wise to utilize multiple means of giving. For example, companies who want to increase the happiness and job satisfaction of their employees should try incorporating several strategies, such as offering employees a small amount of money to spend on their colleagues as well as the opportunity to allocate the company's charitable funds.

\section{Conclusion}

This chapter explored prosocial spending as a mechanism for positive social change. To do so, we began reviewing our research that demonstrates the positive mood and health outcomes associated with prosocial spending for the individual spender. We then extended our discussion to include an examination of the effects of prosocial spending for other individuals, such as the recipient and others nearby: Recipients are happiest after receiving an act of prosocial spending that facilitates positive interpersonal contact. Further, we demonstrated the positive impact of prosocial spending on job satisfaction, team success, and company sales. Finally, we also presented data showing that prosocial spending may provide a route to sustainable happiness for the spender and encourage similar outward spirals of prosocial behavior in others. Indeed, just as the happiness one experiences after engaging in or recalling an act of prosocial spending encourages a future willingness to spend on others again, benefiting from an act of prosocial spending may spur individuals to pay the favor forward. In sum, our research on prosocial spending offers further support for the notion that the findings of positive psychology can reach beyond the individual and inspire positive outcomes on a greater scale.

\section{References}

Aderman, D. (1972). Elation, depression, and helping behavior. Journal of Personality and Social Psychology, 24, 91-101.

Ahuvia, A. (2008). If money doesn't make us happy, why do we act as if it does? Journal of Economic Psychology, 29, 491-507.

Aknin, L. B., Barrington-Leigh, C. P., Dunn, E. W., Helliwell, J. F., Biswas-Diener, R., Kemeza, I., et al. (2010). Prosocial spending and well-being: Cross-cultural evidence for a psychological universal. Unpublished data.

Aknin, L. B., Dunn, E. W., \& Norton, M. I. (2010). Positive feedback loop between prosocial spending and happiness. Unpublished data.

Aknin, L. B., Dunn, E. W., Sandstrom, G., \& Norton, M. I. (2010). Putting the social in prosocial spending. Manuscript in preparation. 
Aknin, L. B., Norton, M. I., \& Dunn, E. W. (2009). From wealth to well-being? Money matters, but less than people think. Journal of Positive Psychology, 4, 523-527.

Algoe, S. B., Haidt, J., \& Gable, S. L. (2008). Beyond reciprocity: Gratitude and relationships in everyday life. Emotion, 8, 425-429.

Anik, L., Aknin, L. B., Norton, M. I., \& Dunn, E. W. (2010). Feeling good about giving: The benefits (and costs) of self-interested charitable behavior. In D. M. Oppenheimer \& C. Y. Olivola (Eds.). Experimental approaches to the study of charitable giving (pp. 3-13). London, England: Psychology Press.

Aversa, J. (2010). Americans' job satisfaction falls to an all time low. Retrieved January 5, 2010, from http://finance.yahoo.com/news/Americans-job-satisfaction-apf-1483464009 $. h t m l ? \mathrm{x}=0 \& \mathrm{sec}=$ topStories $\&$ pos $=3 \&$ asset $=\& \operatorname{ccode}=$

Barbaro, M. (2009). Candles, jeans, lipsticks: Products with ulterior motives. Retrieved December 12, 2009, from http://www.nytimes.com/2006/11/13/us/13retail.html

Barton, N., \& Wasley, P. (2009). Online giving slows. Chronicle of Philanthropy. http://philanthropy.com/free/articles/v21/i14/14001701.htm

Baumeister, R. F., \& Leary, M. R. (1995). The need to belong: Desire for interpersonal attachments as a fundamental human motivation. Psychological Bulletin, 117, 497-529.

Cohen, S., \& Pressman, S. D. (2006). Positive affect and health. Psychological Science, 15, 122-125.

Cunningham, M. R., Steinberg, J., \& Grev, R. (1980). Wanting to and having to help: Separate motivations for positive mood and guilt-induced helping. Journal of Personality and Social Psychology, 38, 181-192.

Deaton, A. (2008). Income, health, wellbeing around the world: Evidence from the Gallup World Poll. Journal of Economic Perspectives, 22, 53-72.

Deci, E. L., \& Ryan, R. M. (1985). Intrinsic motivation and self-determination in human behavior. New York: Plenum.

Dickerson, S. S., \& Kemeny, M. E. (2004). Acute stressors and cortisol responses: A theoretical integration and synthesis of laboratory research. Psychological Bulletin, 130, 355-391.

Diener, E., \& Biswas-Diener, R. (2002). Will money increase subjective well-being? A literature review and guide to needed research. Social Indicators Research, 57, 119-169.

Diener, E., \& Seligman, M. E. P. (2002). Very happy people. Psychological Science, 13, 81-84.

Diener, E., \& Seligman, M. E. P. (2004). Beyond money: Towards an economy of well-being. Psychological Science, 5, 1-31.

Dunn, E. W., Aknin, L. B., \& Norton, M. I. (2008). Spending money on others promotes happiness. Science, 319, 1687-1688.

Dunn, E. W., Ashton-James, C. E., Hanson, M. D., \& Aknin, L. B. (2010). On the costs of selfinterested economic behavior: How does stinginess get under the skin? Journal of Health Psychology, 15, 627-633.

Emmons, R. A., \& McCullough, M. E. (2003). Counting blessings versus burdens: An experimental investigation of gratitude and subjective well-being in daily life. Journal of Personality and Social Psychology, 84, 377-389.

Fowler, J. H., \& Christakis, N. A. (2008). Dynamic spread of happiness in a large social network: Longitudinal analysis over 20 years in Framingham heart study. British Medical Journal, 337, a2338.

Frank, R. H. (2004). How not to buy happiness. Daedalus, 133, 69-79.

Fredrickson, B. L. (1998). What good are positive emotions? Review of General Psychology, 2, 300-319.

Fredrickson, B. L. (2001). The role of positive emotions in positive psychology: The broaden-andbuild theory of positive emotions. American Psychologist, 56, 218-226.

Fredrickson, B. L. (2004). The broaden-and-build theory of positive emotions. Philosophical Transactions of the Royal Society, 359, 1367-1377.

Frey, B. S., \& Stutzer, A. (2000). Happiness, economy and institutions. The Economic Journal, 110, 918-938. 
Glazer, A., \& Konrad, K. A. (1996). A signaling explanation for charity. American Economic Review, 86, 1019-1028.

Hatfield, E., Cacioppo, J. T., \& Rapson, R. L. (1993). Emotional contagion. Psychological Science, 2, 96-99.

Independent Sector. (1999). Giving and volunteering in the United States. http://www. independentsector.org/GandV/default.htm

Isen, A. M. (1970). Success, failure, attention and reaction to others: The warm glow of success. Journal of Personality and Social Psychology, 15, 294-301.

Isen, A. M., \& Levin, P. F. (1972). Effect of feeling good on helping: Cookies and kindness. Journal of Personality and Social Psychology, 21, 384-388.

Johnson, D. (2009). Mystery couple starts "magical" chain reaction. Retrieved December 14, 2009, from http://www.nbcphiladelphia.com/news/local-beat/Mystery-Couple-Pay-ItForward-79179347.html?yhp=1

Kahneman, D., Krueger, A. B., Schkade, D., Schwarz, N., \& Stone, A. A. (2006). Would you be happier if you were richer? A focusing illusion. Science, 32, 1908-1910.

Konow, J., \& Earley, J. (2008). The hedonistic paradox: Is homo economicus happier? Journal of Public Economics, 92, 1-33.

Layard, R. (2005). Happiness: Lessons from a new science. London: Penguin Books.

Lucas, R. E. (2001). Pleasant affect and sociability: Towards a comprehensive model of extraverted feelings and behaviors. Dissertation Abstracts International, 61(10-B), 5610, UMI No. AAI9990068.

Lyubomirsky, S., Sheldon, K. M., \& Schkade, D. (2005). Pursuing happiness: The architecture of sustainable change. Review of General Psychology, 9, 111-131.

McCullough, M. E., Emmons, R. A., \& Tsang, J. (2002). The grateful disposition: A conceptual and empirical topography. Journal of Personality and Social Psychology, 82, 112-127.

McCullough, M. E., Kilpatrick, S. D., Emmons, R. A., \& Larson, D. B. (2001). Is gratitude a moral affect? Psychological Bulletin, 127, 249-266.

McCullough, M. E., Kimeldorf, M. B., \& Cohen, A. (2008). An adaptation for altruism? The social causes, social effects, and social evolution of gratitude. Psychological Science, 17, 281-285.

McEwen, B. S. (1998). Protective and damaging effects of stress mediators. New England Journal of Medicine, 338, 171-179.

Myers, D. G. (2000). The funds, friends, and faith of happy people. American Psychologist, 55, 56-67.

Norton, M. I., Aknin, L. B., Anik, L., Dunn, E. W., \& Quoidbach, J. (2010). Prosocial spending increases employee satisfaction and job performance. Manuscript in preparation.

Oswald, A. J. (1997). Happiness and economic performance. The Economic Journal, 107, 1815-1831.

Piliavin, J. A. (2003). Doing well by doing good: Benefits for the benefactor. In C. L. M. Keyes \& J. Haidt (Eds.), The life well-lived (pp. 227-247). Washington, DC: APA.

Polk, D. E., Cohen, S., Doyle, W. J., Skoner, D. P., \& Kirschbaum, C. (2005). State and trait affect as predictors of salivary cortisol in healthy adults. Psychoneuroendocrinology, 30, 261-272.

Rosenhan, D. L., Underwood, B., \& Moore, B. (1974). Affect moderates self-gratification and altruism. Journal of Personality and Social Psychology, 30, 546-552.

Ryan, R. M., \& Deci, E. L. (2000). Self-determination theory and the facilitation of intrinsic motivation, social development, and well-being. American Psychologist, 55, $68-78$.

Schervish, P., \& Szanto, A. (2006). Wealth and giving by the numbers. Excerpts from Wealth \& Giving Forum Gatherings, Issue 2. Published Fall 2006.

Sheldon, K. M., Boehm, J. K., \& Lyubomirsky, S. (in press). Variety is the spice of happiness: The hedonic adaptation prevention (HAP) model. In I. Boniwell \& S. David (Eds.), Oxford handbook of happiness. Oxford: Oxford University Press. 
Strack, F., Schwarz, N., \& Gschneidinger, E. (1985). Happiness and reminiscing: The role of time perspective, affect, and mode of thinking. Journal of Personality and Social Psychology, 49, $1460-1469$.

Thoits, P. A., \& Hewitt, L. N. (2001). Volunteer work and well-being. Journal of Health and Social Behavior, 42, 115-131.

Totterdell, P. (2000). Catching moods and hitting runs: Mood linkage and subjective performance in professional sports teams. Journal of Applied Psychology, 85, 848-859.

Veenhoven, R. (1991). Is happiness relative? Social Indicators Research, 24, 1-34.

Waldfogel, J. (1993). The deadweight loss of Christmas. The American Economic Review, 83, $1328-1336$.

Williams, S., \& Shiaw, W. T. (1999). Mood and organizational citizenship behavior: The effects of positive affect on employee organizational citizenship behavior intentions. Journal of Psychology, 133, 656-668.

Wilson, E. (2009). Shopping for clothing, donating time. Retrieved December 11, 2009, from http://www.nytimes.com/2009/11/12/giving/12BANANA.html?_r=1\&ref=givin 